\title{
A murine mesenchymal stem cell model for initiating events in osteosarcomagenesis points to CDK4/CDK6 inhibition as a therapeutic target
}

Natasja Franceschini ${ }^{1}$, Raffaele Gaeta (iD) ${ }^{2}$, Paul Krimpenfort ${ }^{3}$, Inge Briaire-de Bruijn (iD ${ }^{1}$, Alwine B. Kruisselbrink (iD ${ }^{1}$, Karoly Szuhai (iD ${ }^{4}$, leva Palubeckaitè (iD) ${ }^{1}$, Anne-Marie Cleton-Jansen (iD) ${ }^{1}$ and Judith V. M. G. Bovée (iD ${ }^{1 \times}$

(C) The Author(s) 2021

Osteosarcoma is a high-grade bone-forming neoplasm, with a complex genome. Tumours frequently show chromothripsis, many deletions, translocations and copy number alterations. Alterations in the p53 or Rb pathway are the most common genetic alterations identified in osteosarcoma. Using spontaneously transformed murine mesenchymal stem cells (MSCs) which formed sarcoma after subcutaneous injection into mice, it was previously demonstrated that p53 is most often involved in the transformation towards sarcomas with complex genomics, including osteosarcoma. In the current study, not only loss of p53 but also loss of $\mathrm{p} 16^{\text {Ink4a }}$ is shown to be a driver of osteosarcomagenesis: murine MSCs with deficient p1 $5^{\operatorname{lnk} 4 b}, \mathrm{p} 16^{\operatorname{lnk} 4 a}$, or p19 ${ }^{\text {Arf }}$ transform earlier compared to wild-type murine MSCs. Furthermore, in a panel of nine spontaneously transformed murine MSCs, alterations in $\mathrm{p} 15^{\mathrm{Ink} 4 \mathrm{~b}}, \mathrm{p} 16^{\text {Ink4a }}$, or $\mathrm{p} 19^{\text {Arf }}$ were observed in eight out of nine cases. Alterations in the Rb/p16 pathway could indicate that osteosarcoma cells are vulnerable to CDK4/CDK6 inhibitor treatment. Indeed, using two-dimensional $(n=7)$ and threedimensional $(n=3)$ cultures of human osteosarcoma cell lines, it was shown that osteosarcoma cells with defective p16 ${ }^{\text {INK4A }}$ are sensitive to the CDK4/CDK6 inhibitor palbociclib after 72-hour treatment. A tissue microarray analysis of 109 primary tumour biopsies revealed a subset of patients (20-23\%) with intact Rb, but defective p16 or overexpression of CDK4 and/or CDK6. These patients might benefit from CDK4/CDK6 inhibition, therefore our results are promising and might be translated to the clinic.

Laboratory Investigation (2022) 102:391-400; https://doi.org/10.1038/s41374-021-00709-z

\section{INTRODUCTION}

Osteosarcoma is the most common malignant mesenchymal tumour of the bone in children and adolescents and characterized by osteoid formation. Compared to other cancer types driven by a specific mutation, osteosarcomas show highly complex genomes with a relatively high occurrence of chromoanagenesis, such as chromothripsis $^{1-3}$. Recurrent alterations are rare, but most often osteosarcomas harbour loss-of-function alterations in TP53 $(47-90 \%)^{1,4,5}$. The second most common alteration inactivates RB1 $(29-47 \%)^{4,5}$, a tumour suppressor gene controlling cell cycle progression 6 . Other regulators of the cell cycle pathway are also often affected in osteosarcoma. CDK4 is amplified in $10 \%$ of highgrade osteosarcomas, and together with CDK6 directly controls $\mathrm{Rb}$ activity by phosphorylation of $\mathrm{Rb}^{7-9}$. Upstream of the $\mathrm{Rb}$ pathway, p15 ${ }^{\mathrm{INK} 4 \mathrm{~B}}$ and $16^{\mathrm{INK} 4 \mathrm{~A}}$ can inhibit CDK4 and CDK6 activity. p15 ${ }^{\text {INK4b }}$ is transcribed from the CDKN2B gene, whereas $\mathrm{p} 16^{\text {INK4A }}$, and its alternate reading frame $\mathrm{p} 14^{\mathrm{ARF}}$ (p19 $19^{\mathrm{Arf}}$ in mouse), is transcribed from the CDKN2A gene (a schematic overview of the locus is depicted in Supplementary Fig. S1). p14 $4^{A R F} / \mathrm{p} 19^{\text {Arf }}$ is involved in activating p53-dependent growth arrest ${ }^{10}$. CDKN2B and CDKN2A are adjacent loci on the genome and are often codeleted. Somatic alterations in both genes have been identified in
14-19\% of osteosarcomas and also often in other tumour types $^{11,12}$. In particular, deletions of CDKN2A are clinically relevant, as loss of p16 $16^{\mathrm{INK} 4 \mathrm{~A}}$ is correlated with poor overall survival and poor response to chemotherapy ${ }^{13-18}$.

We previously demonstrated that murine and canine mesenchymal stem cells (MSCs) spontaneously transform in vitro and can be used to model driver or initiating events involved in the development of sarcomas with complex genomics, including osteosarcoma $^{19}$. We showed that spontaneously transformed murine MSCs harbour point mutations in Trp53 and/or copy number alterations in $C d k n 2 a$ and $C d k n 2 b$. Upon inactivation of Trp53, murine MSCs transformed earlier compared to wild-type, confirming the contribution of loss of p53 to spontaneous transformation and development of sarcomas with a complex genome.

In the current study, we investigate the role of the Cdkn2a/ $C d k n 2 b$ genes in the spontaneous transformation of murine MSCs towards osteosarcoma. We show that murine MSCs with deficient p15 $5^{\text {Ink4b }}$ p16 $6^{\text {Ink4a }}$, or p19 Arf transform earlier compared to wildtype MSCs. Furthermore, we demonstrate that the defective cell cycle regulation pathway caused by $\mathrm{p} 16^{\mathrm{INK} 4 \mathrm{~A}}$ inactivation can be therapeutically exploited using the selective CDK4/CDK6 inhibitor

\footnotetext{
${ }^{1}$ Department of Pathology, Leiden University Medical Center, Leiden, The Netherlands. ${ }^{2}$ Department of Translational Research and New Technologies in Medicine and Surgery, University of Pisa, Pisa, Italy. ${ }^{3}$ Division of Molecular Genetics, The Netherlands Cancer Institute, Amsterdam, The Netherlands. ${ }^{4}$ Department of Cell and Chemical Biology, Leiden University Medical Center, Leiden, The Netherlands. ${ }^{凶}$ email: j.v.m.g.bovee@lumc.nl
}

Received: 16 August 2021 Revised: 7 November 2021 Accepted: 19 November 2021

Published online: 17 December 2021 
palbociclib in both 2D and 3D in vitro culture models of osteosarcoma cell lines. Our study demonstrates that $20-23 \%$ of primary osteosarcoma biopsies showed intact $\mathrm{Rb}$, but defective p16 ${ }^{\text {INK4A }}$ or overexpression of CDK4 and/or CDK6, indicating potential benefit from CDK4/CDK6 inhibition in almost one quarter of osteosarcoma patients.

\section{MATERIALS AND METHODS Cell culture}

Murine bone-marrow derived mesenchymal stem cells (MSCs) were isolated as described previously ${ }^{19}$, from surplus C57BL/6 J (B6_4, B6_5, B6_7, B6_10), surplus NMRI (NMRI_2, NMRI_3, NMRI_9) mice, or C57BL/6 J mice kindly gifted by Dr. Melissa van Pel (BM42, BM91). Growth curves, differentiation capacity, in vivo growth capacity and a detailed genomic analysis using whole genome sequencing have been described elsewhere for B6_4, B6_7, B6_10 ${ }^{19}$. Additional murine MSCs were isolated from surplus FVB mice and mice with deficient p15 $5^{\operatorname{lnk} 4 b}\left(\operatorname{Ink} 4 \mathrm{~b}^{-1-}\right), \mathrm{p} 16^{\operatorname{lnk} 4 a}$

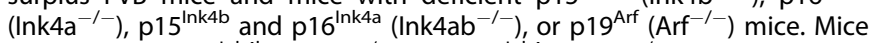
with deficient p15 $5^{\text {Ink4b- }}\left(\right.$ Ink $\left.4 b^{-1-}\right)$ and p1 $6^{\text {Ink4a }}\left(\right.$ Ink4a $\left.{ }^{--}\right)$were generated as described previously ${ }^{20}$ (Supplementary Fig. S1). Genetic knockout was confirmed at the protein level by Western blotting and for Ink4ab ${ }^{-1-}$ mice also at the DNA level by PCR using 5'GCAGTGTTGCAGTTTGAACCC $3^{\prime}$ as a forward primer and $5^{\prime}$ TGTGGCAACTGATTCAGTTGG $3^{\prime}$ as a reverse primer ${ }^{20}$. All murine MSCs were cultured in alpha MEM (Gibco, Invitrogen Life Technologies, Scotland, UK) supplemented with $15 \%$ Performance plus fetal bovine serum (FBS) (Gibco), 1\% Pen/Strep (Gibco), and 1\% Glutamax (Gibco) at $37^{\circ} \mathrm{C}$ with $5 \% \mathrm{CO}_{2}$ in a humidified incubator and were tested regularly for mycoplasma. Each passage cells were trypsinized and counted with a Bürker-Türk counting chamber to calculate population doublings.

Human osteosarcoma cell lines 143B, MG63, MHM, SAOS2, ZK58, HAL and KPD were cultured in RPMI 1640 (Gibco), supplemented with 10\% FBS, in a humidified incubator at $37^{\circ} \mathrm{C}$ and $5 \% \mathrm{CO}_{2}$. Human cell lines were retrieved from the EuroBoNet consortium ${ }^{21}$ and were regularly STR profiled using the GenePrint 10 system kit (Promega, Madison, WI, USA) and tested for mycoplasma. For the generation of multi-cellular tumour spheroids (MCTS) of osteosarcoma cell lines (protocol adapted from ref. ${ }^{22}$ ), cells were suspended in medium combined with methylcellulose $(0.24 \%(\mathrm{w} / \mathrm{v})$ dissolved in DMEM), and seeded into a $1 \%$ agarose coated $96-$ well plate for seven days before the start of an experiment.

\section{Drug treatment}

For 2D cultures, human osteosarcoma cell lines or murine MSCs were seeded (between 3000 and 6000 cells per well) into 96-well plates and after $24 \mathrm{~h}$ treated with PBS or Palbociclib (dissolved in PBS, PD-0332991, Selleckchemicals, Houston, TX, USA) in concentrations ranging from 0.01 $\mu \mathrm{M}$ to $100 \mu \mathrm{M}$. Cells were fixed three days after treatment with $4 \%$ formaldehyde and stained with $2 \mu \mathrm{g} / \mathrm{ml}$ Hoechst (Invitrogen Life Technologies, Thermo Fisher Scientific, MA, USA) and nuclei were counted with the Cellomics ArrayScan VTI HCS 700 and HCS Studio Cell Analysis Software (Thermo Fisher Scientific). For MCTS, cells were treated with PBS or palbociclib in concentrations ranging from $0.1 \mu \mathrm{M}$ to $100 \mu \mathrm{M}$. Cells were incubated three days after treatment with PrestoBlue cell viability reagent (Invitrogen Life Technologies) for $90 \mathrm{~min}$ and fluorescence was measured using a microplate reader (Infinite M Plex, Tecan Group Ltd., Zürich, Switzerland). After read-out, MCTS were fixed in $4 \%$ formaldehyde containing Alcian Blue (1:400) and paraffin embedded. To determine cell viability relative to PBS control, dose response curves were made using Graphpad Prism 8 software, after correcting for background reads and normalized growth rates of each cell line, as described previously ${ }^{23}$.

\section{Transformation analysis of mesenchymal stem cells}

Late passage ( $>$ passage 8 ) murine MSCs were subjected to metaphase analysis and the soft agar anchorage independent growth assay as described previously ${ }^{19}$. In short, for metaphase harvest murine MSCs were seeded and treated with Calyculin A ( $80 \mathrm{nM}$, LC Laboratories, Woburn, MA, USA). Hereafter, cells were washed, incubated with $\mathrm{KCl}(0.075 \mathrm{M})$ and fixed with methanol/glacial acetic acid in a ratio of $4: 1$. The cell suspension was dropped onto a slide and stained with DAPI for microscopic counting of metaphase chromosomes. For the soft agar anchorage independent growth assay, a cell suspension of 50,000 cells were seeded into a top layer of $0.35 \%$ agarose, on top of a bottom layer of $0.7 \%$ agarose in non-tissue culture treated 6-well plates and incubated in a humidified incubator at $37^{\circ} \mathrm{C}$ with $5 \% \mathrm{CO}_{2}$ for 4 weeks, after which cells were imaged with GelCount (Oxford Optronix, Milton, UK). Previously transformed cells $\left(B 6 \_10\right)^{19}$ were taken along as a positive control.

\section{Western blotting}

For p15, p16, Rb and GAPDH Western blots, whole cell Hot-SDS lysates of murine MSCs or osteosarcoma cell lines were collected as described previously ${ }^{19}$. For $\mathrm{p} 19$ and Histon H3 western blots, nuclear lysates were made by washing cells twice with cold PBS, followed by the addition of PBS-Triton X (0.5\%) for $10 \mathrm{~min}$, while shaking on ice. Cells were centrifuged twice, washed with PBS-Triton $X(0.5 \%)$ and the pellet was resuspended in Hot-SDS buffer ( $1 \%$ SDS, $10 \mathrm{mM}$ EDTA, $10 \mathrm{mM}$ Tris pH 7.4) containing protease inhibitor cocktail (Roche, Basel, Switzerland) and phosphatase inhibitor cocktail (Roche). Protein concentrations of lysates were determined with the Biorad DC ${ }^{\mathrm{TM}}$ protein assay kit (Bio-rad, Hercules, CA, USA) according to the manufacturer's protocol, measured with a microplate reader (Infinite M Plex, Tecan Group Ltd.).

Sample loading, blotting and quantification were performed as previously described $^{19}$. Blots were stained for p15 (1:500, Abcam, Cambridge, UK), p16 (1:1000, clone JC8, Immunologic, WellMed BV, Duiven, The Netherlands), p19 (1:5000, clone ab80, Abcam), Rb (1:500, clone G3-245, BD Pharmingen, San Diego, CA, USA), Histon H3 (1:1000, Cell Signalling, Leiden, The Netherlands), or GAPDH (1:3000, Cell Signalling). Blots were developed with SuperSignal West Pico PLUS Chemiluminescent Substrate (Thermo Fisher Scientific) using the ChemiDoc Touch Imaging System (Bio-rad).

\section{Immunohistochemistry}

Tissue micro array construction. For this study five osteosarcoma tissue micro arrays (TMA) were used, that contain FFPE samples of primary tumour biopsies, primary tumour resections, local relapses and metastases of 158 patients (not all sample types were available for each patient). Clinicopathological details can be found in Supplementary Table S1. Good histological response to chemotherapy was defined as $\geq 90 \%$ tumour necrosis after chemotherapy ${ }^{24}$. The construction of one of the TMAs has been described previously (cohort 2) ${ }^{25,26}$. For the construction of TMAs for cohorts 1,3 , and 4 , punches $(1.0 \mathrm{~mm}$ (cohort 3 ) or $1.5 \mathrm{~mm}$ (cohort 1and 4)) of FFPE samples were placed into an acceptor block using the TMA master (3DHISTECH, Budapest, Hungary). For each tumour, three tissue-cores were present in the same block. For cutting sections, the tape transfer system (39475205, Leica Biosystems, Wetzlar, Germany) was used. Each TMA also contained other tissue types as internal controls for immunohistochemistry.

Immunohistochemical staining. Slides of each TMA or slides containing sections $(4 \mu \mathrm{m})$ of paraffin embedded MCTS were stained with haematoxylin and eosin (H\&E) or used for immunohistochemical staining after deparaffinisation and rehydration. TMA sections were stained for CDK6 (151213, Abbiotec, San Diego, CA, USA), CDK4 (12790, clone D9G3E, Cell Signaling) or Rb (554136, clone G3245, BD Pharmingen). MCTS sections were stained for Rb, Ki67 (clone D2H10, Cell Signaling), cleaved caspase 3 (Cell Signaling), and SATB2 (clone CL0276, Sigma). For CDK6, SATB2, Ki67 and cleaved caspase 3 staining, antigen retrieval was performed by incubation in $10 \mathrm{mM}$ citrate buffer (pH 6) for $10 \mathrm{~min}$ and cooling down for $2 \mathrm{~h}$. For CDK4 and Rb staining, antigen retrieval was performed in TrisEDTA (pH 9). Sections were incubated with primary antibody (Ki67, 1:1600; cleaved caspase 3, 1:800; CDK4, 1:4000; CDK6, 1:100; Rb, 1:2000, SATB2, 1:10) overnight at $4{ }^{\circ} \mathrm{C}$. The next day, sections were incubated with BrightVision one step detection system poly-HRP anti-mouse/rabbit (VWRKDPVO110HRP, Immunologic) for $30 \mathrm{~min}$. Sections were then washed with PBS and DAB+Chromogen (K3468, Dako, Agilent Technologies, CA, USA) was added to each slide for $10 \mathrm{~min}$. Slides were counterstained with haematoxylin, dehydrated and mounted.

Immunohistochemical scoring. For TMAs two independent observers (N.F. and R.G.) scored each core semi-quantitatively based on the intensity of the staining and percentage of positive cells, as described previously ${ }^{27}$. For intensity, a value of 1 (weak), 2 (moderate), or 3 (strong) was given, and for the percentage of positive cells, a value of $1(0-24 \%), 2(25-49 \%), 3$ $(50-74 \%)$, or $4(75-100 \%)$. For CDK4 and Rb the staining was nuclear, but for CDK6 both nuclear and cytoplasmic staining was evaluated. Tumours were regarded as positive if the sum of scores for intensity and percentage of positive cells was $\geq 4$ for $\mathrm{CDK} 4^{27}$. Tumours were classified as CDK6 high when the sum of cytoplasmic and nuclear scores for CDK6 was $\geq 7^{28}$. Tumours with a sum of scores equal to 0 , yet with a positive internal control, were regarded as negative for $\mathrm{Rb}$ staining. In case of discrepancies 

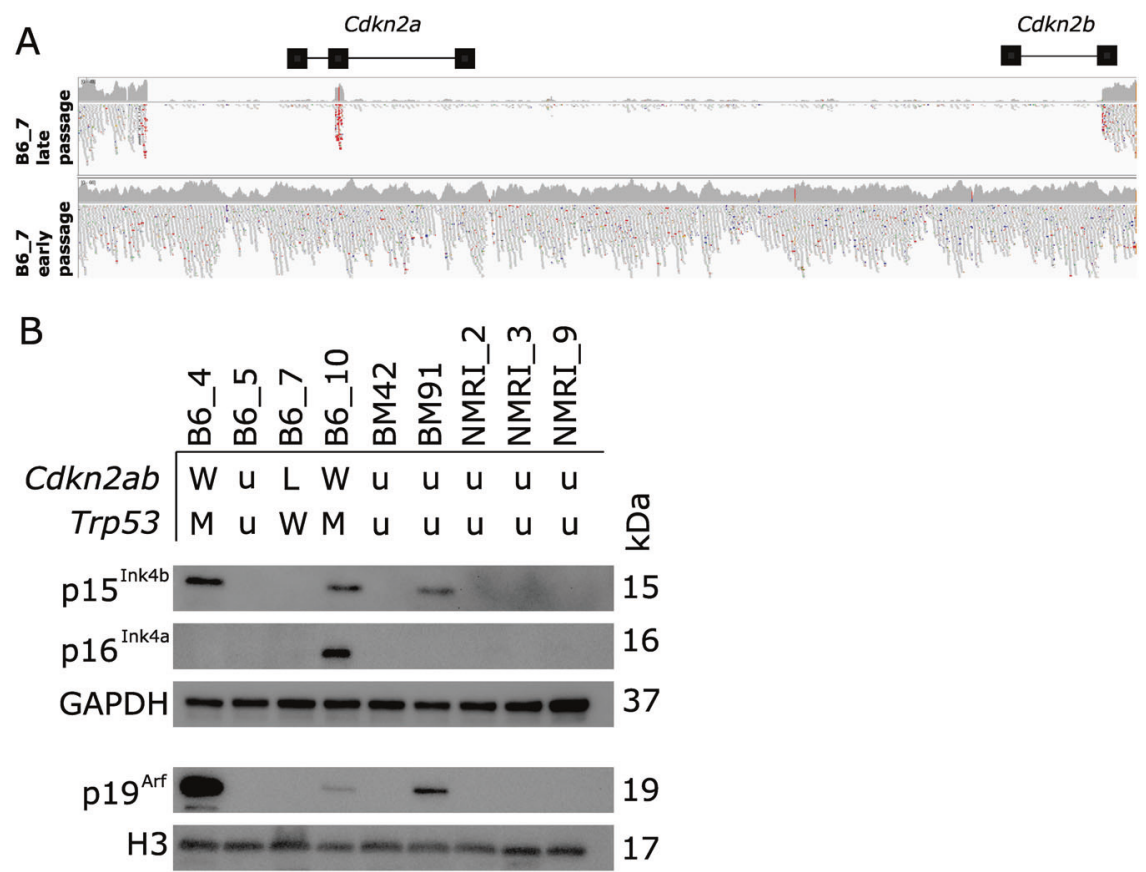

Fig. 1 Transformed murine MSCs of different mouse strains frequently show loss of protein expression of p15 ${ }^{\text {Ink4b }}, \mathrm{p} 16^{\text {Ink4a }}$ and $\mathrm{p} 19^{\text {Arf }}$. A IGV viewer showing a homozygous deletion including both Cdkn2a and Cdkn2b genes in transformed (late passage) murine MSC B6_7. Early passage cells (P2) were collected prior to the transformation event, whereas late passage cells (P15) were collected after spontaneous transformation. B Western blot depicting protein expression of p15 $15^{\text {Ink4b }}, \mathrm{p} 16^{\text {Ink4a }}, \mathrm{p} 19^{\mathrm{Arf}}$ in transformed murine MSCs from C57BL/6 J (B6_4, B6_7, B6_10, BM42, BM91) or NMRI mice (NMRI_2, NMRI_3, NMRI_9). GAPDH or Histon H3 was used as a loading control. The size of each band is indicated in $\mathrm{kDa}$. The genomic status of genes Cdkn2a, Cdkn2b, and Trp53 is indicated for transformed murine MSCs as described previously ${ }^{19} . \mathrm{M}=$ point mutation, $\mathrm{W}=$ wildtype, $\mathrm{L}=$ homozygous loss, $\mathrm{u}=$ no genomic status available.

between the two observers, slides were reviewed by a third observer (J.V. M.G.B.) to reach a consensus. For quantification of MCTS, the number of positive cells of cleaved caspase 3 and Ki67 stainings was determined using QuPath Software v.0.2.3 on three different sections on each slide ${ }^{29}$.

\section{Statistical analysis}

For statistical comparisons between two groups, a Student's $t$ test was performed. Correlation analysis was performed using Spearman's correlation. Comparisons between survival curves were performed using the Logrank (Mantel-Cox) test. All statistical analyses were performed using GraphPad Prism v.8. Comparisons were considered statistically significant using a significance level of $5 \%$.

\section{RESULTS}

Loss of CDKN2A/CDKN2B is frequent in spontaneously transformed murine MSCs

We previously identified a large deletion in the $C d k n 2 a / C d k n 2 b$ locus in one of three transformed murine MSC cultures (B6_7), that formed sarcoma in vivo ${ }^{19}$, for which the $C d k n 2 a / C d k n 2 b$ locus is shown in Fig. 1A. To evaluate the relevance of $C d k n 2 a$ and $C d k n 2 b$ loss we used a larger panel of nine spontaneously transformed murine MSCs, originating from different strains (C57BL/6 J or NMRI), for expression of $\mathrm{p} 15^{\operatorname{lnk} 4 \mathrm{~b}}, \mathrm{p} 16^{\operatorname{lnk} 4 a}$ and $\mathrm{p} 19^{\mathrm{Arf}}$ at the protein level. Transformation of six out of nine murine MSC lines have been described elsewhere (B6_4, B6_7, B6_10, NMRI_2, NMRI_3, NMRI_9 ${ }^{19}$. For the additional three lines, the transformation event was confirmed by karyotyping (B6_5, BM42, BM91; Supplementary Fig. S2). Transformed murine MSC line B6_7 indeed showed loss of protein expression of $\mathrm{p} 15^{\operatorname{lnk} 4 b}, \mathrm{p} 16^{\operatorname{lnk} 4 a}$ and $\mathrm{p} 19^{\text {Arf }}$. Furthermore, loss of $\mathrm{p} 15^{\text {lnk4b }}, \mathrm{p} 16^{\operatorname{lnk} 4 a}$ or p19 $19^{\text {Arf }}$ is a common event, as six out of nine MSCs have lost $\mathrm{p} 15^{\operatorname{lnk} 46}$ expression, and six out of nine MSCs have lost p19Arf expression (Fig. 1B). Eight out of nine MSCs show loss of p16 $6^{\text {Ink4a }}$ expression. However, in this Western blot loss of p16 1 ink4a protein expression is not always indicative for $\mathrm{p} 16^{\text {Ink4a }}$ deletion on genomic level, illustrated for instance by murine MSC line B6_4 that has intact $\mathrm{p} 16^{\text {Ink4a }}$ based on whole-genome sequencing data $(\text { Fig. } 1 \mathrm{~B})^{19}$, but does not show p16 $6^{\text {Ink4a }}$ protein expression.

\section{Murine MSCs deficient for $\mathrm{p} 16^{\text {Ink4a }}$ and deficient for $\mathrm{p} 15^{\text {Ink4b }}$} transform earlier compared to wildtype MSCs

To evaluate whether loss of $\mathrm{p} 16^{\operatorname{lnk} 4 a}$ and $\mathrm{p} 15^{\operatorname{lnk} 4 \mathrm{~b}}$ or both is important in the spontaneous transformation of murine MSCs, MSCs from mice with loss of $\mathrm{p} 16^{\operatorname{lnk} 4 a}\left(\operatorname{Ink} 4 \mathrm{a}^{-/-}\right)$, loss of $\mathrm{p} 15^{\operatorname{lnk} 4 \mathrm{~b}}$ $\left(\right.$ Ink $\left.4 b^{-1-}\right)$, or both $\left(\operatorname{Ink} 4 a b^{-1-}\right)$ were cultured long-term to observe when transformation would occur (for a schematic overview of the knockout mice used in this study see Supplementary Fig. S1). Murine MSCs from Ink4a $a^{-/-}$, Ink4b $b^{-/-}$or Ink4ab ${ }^{-1-}$ mice transformed earlier (after 25-46 days) compared to wild-type murine MSCs (after 64-76 days) (Fig. 2A). As the Cdkn2a gene also encodes an alternative reading frame, p19 $9^{\text {Arf }}$, murine MSCs with a loss of p19 Arf were cultured and also shown to transform earlier (after 23 days) compared to wildtype MSCs (after 61 days) (Fig. 2B). For all knockout mice, the knockout was confirmed by Western blotting and for mice with deficient p16 ${ }^{\text {Ink4a }} ;$ p15 $5^{\text {Ink4b }}\left(\right.$ Ink4ab $\left.{ }^{-/-}\right)$mice also at the DNA level by PCR (Supplementary Fig. S3). Transformation of murine MSCs was confirmed by metaphase analysis (Fig. 2C), as late passage MSCs had higher than the normal modal number of 40 chromosomes. However, none of the knockout MSCs showed soft agar anchorage independent growth (Fig. 2D). These results show that loss of p16 $16^{\operatorname{lnk} 4 a}$ and/or p15 1 Ink4b enhanced proliferation and genomic alterations suggesting transformation.

Transformed murine MSCs with loss of $\mathrm{p} 16^{\operatorname{lnk4a}}$ and $\mathrm{p} 15^{\text {Ink4b }}$ are sensitive to palbociclib

Within the Rb pathway, the Ink4 proteins inhibit CDK4/CDK6 activity, thereby inhibiting cell cycle progression. Therefore loss of p16 $6^{\text {Ink }}$ a and $15^{\text {Ink4b }}$ could make cells more vulnerable to CDK4/ 

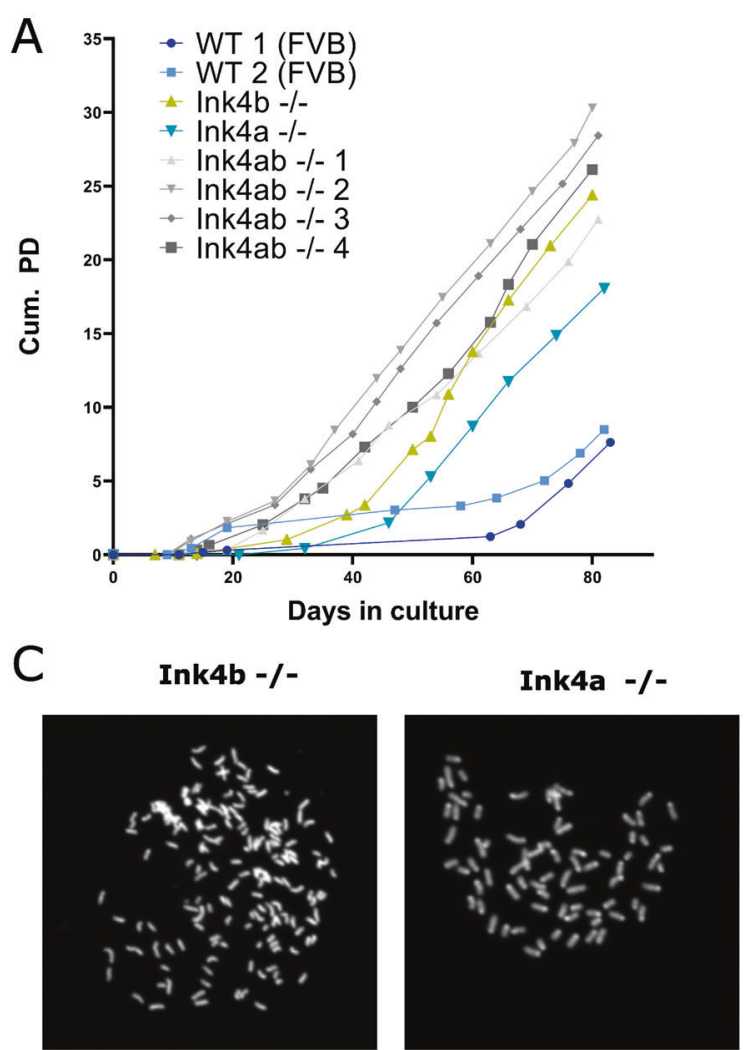

D
B

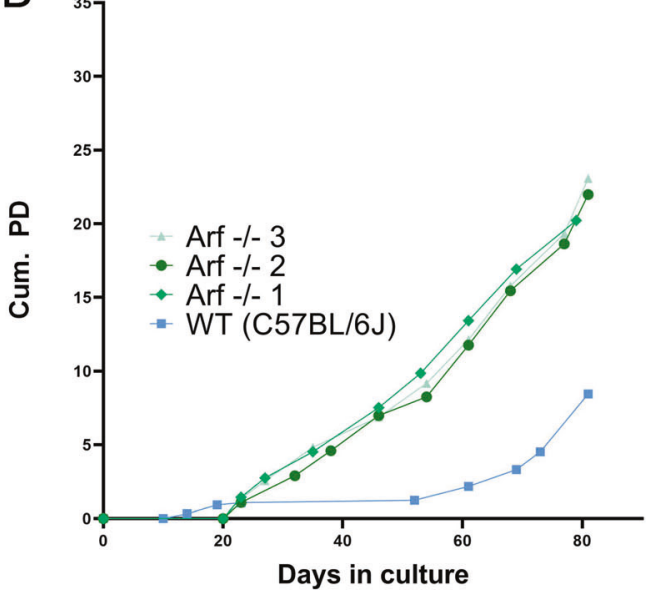

Ink4ab -/-

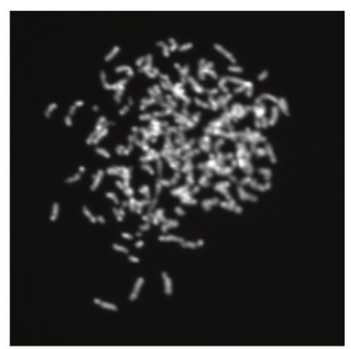

Arf -/-

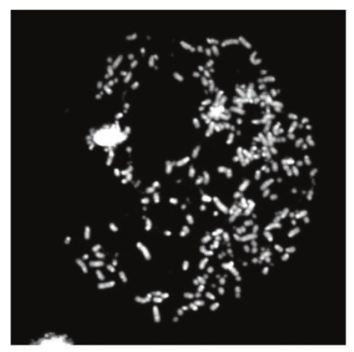

B6_10

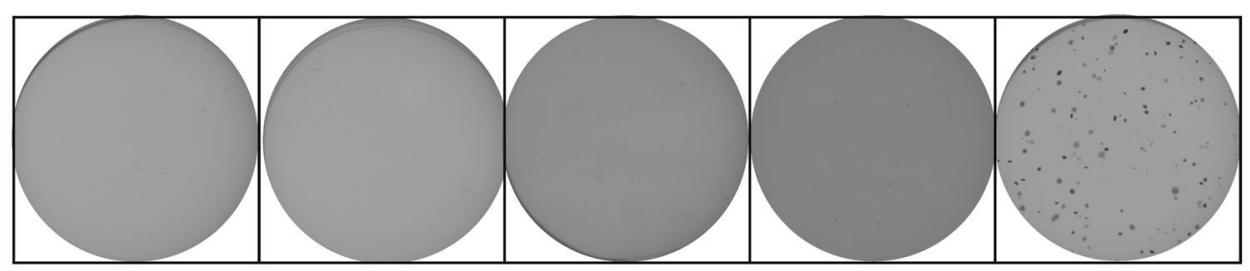

Fig. 2 Earlier transformation of p16 or p15 knockout MSCs. Murine MSCs isolated from A $\operatorname{lnk} 4 a^{-1-}(n=1), \operatorname{lnk} 4 \mathrm{~b}^{-1-}(n=1), \operatorname{lnk} 4 a b^{-1-}(n=$ 4) $\mathbf{B}$ or $\operatorname{Arf}^{-1-}(n=3)$ transform earlier compared to wild-type MSCs from FVB or C57BL/6 J mice, based on cumulative population doublings (Cum. PD.). Each datapoint represents a passage of the cell culture. C Metaphase analysis of murine MSCs from Ink4a ${ }^{-1-}$, Ink4b ${ }^{-1-}$, Ink4ab ${ }^{-1-}$, or $\mathrm{Arf}^{-1-}$ mice showed abnormal chromosome numbers, higher than the normal modal number of 40 . D Soft agar anchorage independent

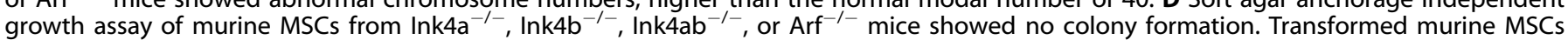
from B6_10 were used as a positive control.

CDK6 inhibitors to decrease uncontrolled cell proliferation. To investigate this in our murine mesenchymal stem cell model, transformed murine MSCs, in which p $16^{\text {Ink4a }}$ and $\mathrm{p} 15^{\text {Ink4b }}$ loss was confirmed, were treated with the CDK4/CDK6 inhibitor palbociclib. Murine MSCs in which whole-genome sequencing previously confirmed loss of p16 ${ }^{\text {Ink4a }}$ and p15 $15^{\operatorname{lnk} 4 b}\left(B 6 \_7\right)^{19}$ were more sensitive to palbociclib, with an $\mathrm{IC}_{50}$ of $0.5 \mu \mathrm{M}$ compared to transformed MSCs that have intact p16 $6^{\text {Ink4a }}$ and p1 $5^{\text {Ink4b }}$ (B6_4 and B6_10), with $I C_{50}$ values of 3.6 and $10.3 \mu \mathrm{M}$, respectively (Fig. 3A). To determine whether the increased sensitivity was caused by loss of $\mathrm{p} 16^{\operatorname{lnk} 4 a}$ and $\mathrm{p} 15^{\operatorname{lnk} 4 \mathrm{~b}}$, murine MSCs isolated from Ink4ab ${ }^{-1-}$ mice were treated with palbociclib (Fig. 3B). MSCs from Ink4ab ${ }^{-1-}$ mice showed the highest sensitivity to palbociclib, with $\mathrm{IC}_{50}$ values between 0.8 and $1.2 \mu \mathrm{M}$, compared to wild-type MSCs, with an $\mathrm{IC}_{50}$ of $8.3 \mu \mathrm{M}$, suggesting that loss of $\mathrm{p} 16^{\text {lnk4a }}$ and $\mathrm{p} 15^{\text {lnk4b }}$ increases sensitivity to palbociclib.

\section{Human osteosarcoma cell lines are sensitive to palbociclib}

Osteosarcoma cell lines were treated with palbociclib in 2D cultures and $\mathrm{IC}_{50}$ values were determined (Fig. 4A). A highly variable dose-dependent response to palbociclib in all osteosarcoma cell lines was observed. As the efficacy of CDK4/CDK6 inhibition relies on the presence of intact $\mathrm{Rb}$, the $\mathrm{Rb}$ status of each osteosarcoma cell line was determined by Western blot. All osteosarcoma cell lines (143B, MG63, MHM, HAL and KPD), except for SAOS2 and ZK58, showed Rb expression (Fig. 4B). SAOS2 and ZK58, with loss of $\mathrm{Rb}$, indeed showed the highest $\mathrm{IC}_{50}$ of palbociclib compared to other osteosarcoma cell lines. However, the difference in IC 50 value between ZK58 and other osteosarcoma cell lines with intact $\mathrm{Rb}$ was smaller than for SAOS2. The expression status of other proteins involved in the p16-Rb pathway was investigated, including $\mathrm{p} 16^{\mathrm{INK} 4 \mathrm{~A}}, \mathrm{CDK} 4$ and CDK6. p16 ${ }^{\text {INK4A }}$ protein expression of each cell line was based on immunohistochemical expression published previously ${ }^{21}$ (Fig. 1B). The p16 immunohistochemical status of each cell line was combined with the $I C_{50}$ values from the current study. Although osteosarcoma cells with loss of $\mathrm{p} 16^{\mathrm{INK} 4 \mathrm{~A}}$ showed on average a lower $I C_{50}$ to palbociclib $(1.4 \mu \mathrm{M})$ than cells with normal p16 $6^{\mathrm{INK} 4 \mathrm{~A}}$ expression $(4.1 \mu \mathrm{M})$, this difference was not statistically significant $(p=0.3)$ (Fig. 4C). CDK4 and CDK6 RNA expression levels were 
A

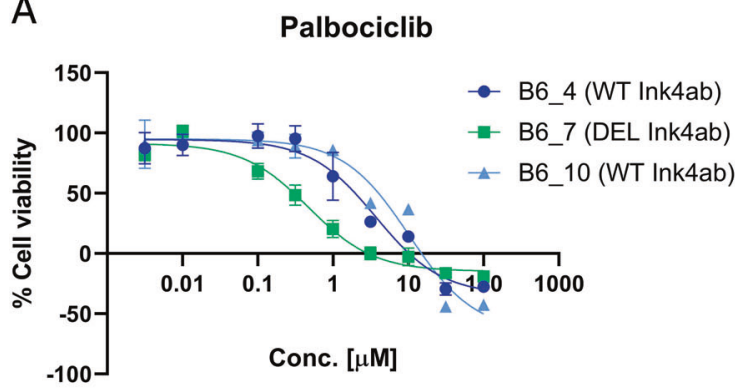

B

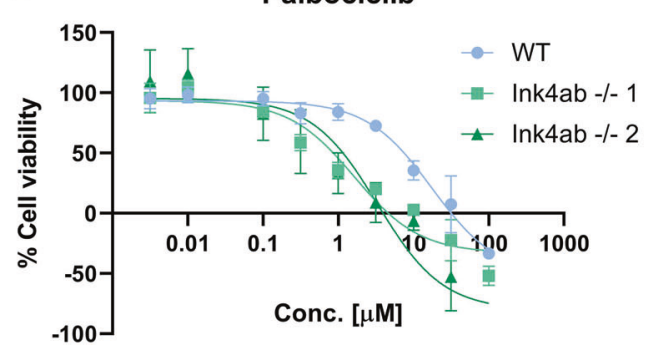

\begin{tabular}{|l|l|}
\hline Cell line & IC50 $(\mu \mathrm{M})$ \\
\hline B6_4 & 3.6 \\
\hline B6_7 & 0.5 \\
\hline B6_10 & 10.3 \\
\hline
\end{tabular}

\begin{tabular}{|l|l|}
\hline Cell line & IC50 $(\boldsymbol{\mu M})$ \\
\hline WT & 8.3 \\
\hline Ink4ab -/- 1 & 0.8 \\
\hline Ink4ab -/- 2 & 1.2 \\
\hline
\end{tabular}

Fig. 3 Transformed murine MSCs are sensitive to CDK4/CDK6 inhibitor palbociclib. Murine MSCs (A) that have spontaneously transformed after long-term culture (B6_4, wildtype (WT) Ink4ab; B6_7, deletion (DEL) of Ink4ab; B6_10, wildtype (WT) Ink4ab) or B MSCs from Ink4ab ${ }^{-1-}$ mice after transformation were treated with palbociclib for $72 \mathrm{~h}$ after which relative cell viability and $I C_{50}$ values were determined. Wildtype MSCs were derived from FVB mice. Data points represent the mean of three experiments performed \pm standard deviation.

derived from a previously published dataset $^{30}$, and correlation analysis was performed using $\mathrm{IC}_{50}$ values from the current study. There was no correlation between CDK4 and CDK6 RNA expression and sensitivity to palbociclib in osteosarcoma cell lines (Fig. 4D).

\section{D cultures of osteosarcoma are also sensitive to palbociclib} Since 2D cultures might be less representative for the in vivo situation compared to 3D cultures, as demonstrated in previous studies $^{31-33}$, the response to palbociclib in $3 D$ cultures of osteosarcoma cell lines was investigated. Multi-cellular tumour spheroids (MCTS) of three osteosarcoma cell lines were generated (MHM, SAOS2 and MG63) and histological analysis showed the morphological heterogeneity that is also seen in primary tumours (Fig. 5A). MCTS of SAOS2 and MHM show areas suggestive of extracellular matrix deposition and tumour cells were focally positive for SATB2, a marker for osteogenic differentiation (Fig. 5A). MCTS of all osteosarcoma cell lines showed a dose-dependent decrease in cell viability after treatment with palbociclib (Fig. 5B). The $I C_{50}$ values of $3 D$ cultures were higher compared to $2 \mathrm{D}$ cultures (Fig. 5B). In MCTS of osteosarcoma cell lines MHM and MG63, palbociclib treatment significantly reduced the percentage of proliferating cells and increased apoptosis as evident from Ki67 and cleaved caspase 3 staining, respectively (Fig. 5C).

\section{Protein expression of Rb, CDK4 and CDK6 in osteosarcoma patient primary tumour tissue}

To estimate which percentage of osteosarcoma patients might be eligible for palbociclib treatment, the expression levels of proteins in the p16-Rb pathway, including Rb, CDK4, CDK6 and p16, was determined in primary tumour tissue of 109 patients using TMA (Table 1; Fig. 6A). As Rb status determines the efficacy of CDK4/ CDK6 inhibition ${ }^{34,35}$, first $\mathrm{Rb}$ expression was evaluated. $36.4 \%$ of the osteosarcomas have lost expression of $\mathrm{Rb}$. As palbociclib directly inhibits CDK4 and CDK6, protein expression levels of CDK4 and CDK6 were determined. $23.7 \%$ of primary tumours were CDK4 positive and $44.8 \%$ were CDK6 high. p16 scores have been determined in a previous study in osteosarcoma patients (cohort 2), where $20.5 \%$ of osteosarcoma patients showed loss of $\mathrm{p} 16^{13}$.
As a combination of Rb expression and CDK4/CDK6 expression or loss of p16 expression are expected to imply sensitivity to CDK4/ CDK6 inhibition, the combination scores were determined (Table 1). Of the primary tumour biopsies, $22.7 \%$ of the tumours were positive for both $\mathrm{Rb}$ and CDK4, 52.9\% were positive for $\mathrm{Rb}$ and CDK6, and $43.1 \%$ was positive for Rb, and CDK4 or CDK6. In cohort 2, $13.3 \%$ of the primary tumour biopsies were positive for $\mathrm{Rb}$, but lost p16 expression. In total, between $20.0 \%$ and $23.3 \%$ of the tumours are $\mathrm{Rb}^{\text {positive }} / \mathrm{p} 16^{\text {negative }}, \mathrm{Rb}^{\text {positive }} / \mathrm{CDK} 4^{\text {positive }}$, or $\mathrm{Rb}^{\text {positive }} / \mathrm{CDK} 6^{\text {high }}$, which corresponds to the group of patients that might benefit from CDK4/CDK6 inhibitor treatment. A previous study showed that p16 loss was prognostic for poor overall survival in osteosarcoma patients ${ }^{13}$. In the current study, CDK6 scores were found to be prognostic for overall survival, where patients with overexpression of CDK6 have a worse overall survival compared to those patients with low CDK6 expression (Fig. 6B). For $\mathrm{Rb}$ and CDK4 expression there was no significant difference in survival (Supplementary Fig. S4). Neither Rb, CDK4, or CDK6 scores are prognostic for metastasis-free survival (Supplementary Fig. S4) or response to chemotherapy (not shown).

\section{DISCUSSION}

Transformed murine MSCs provide an excellent model to identify drivers of transformation in osteosarcoma. In addition to p53 alterations $^{19}$, transformed murine MSCs also frequently lose expression of $\mathrm{p} 15^{\operatorname{lnk} 4 \mathrm{~b}}, \mathrm{p} 16^{\operatorname{lnk} 4 a}$ and $\mathrm{p} 19^{\text {Arf }}$. However, the protein expression status did not always correspond to the genomic status, as is evident for MSC line B6_4 with loss of $p 16^{\text {lnk4a }}$ protein expression without concomitant genomic alterations at the CDKN2A locus. Alternative mechanisms of p16 ink4a protein expression loss, such as promotor methylation may be active. Nevertheless, the loss of expression of p15 ${ }^{\text {Ink4b }}, \mathrm{p} 16^{\text {Ink4a }}$ and $\mathrm{p} 19^{\text {Arf }}$ in murine MSCs, reflects the genomic status of human osteosarcoma where alterations in $\mathrm{p} 15^{\mathrm{INK} 4 \mathrm{~B}}, \mathrm{p} 16^{\mathrm{INK} 4 \mathrm{~A}}$, or $\mathrm{p} 14^{\mathrm{ARF}}$ are also frequently found $d^{4,5,7,8,25}$.

This study shows that loss of either $\mathrm{p} 15^{\operatorname{lnk} 4 \mathrm{~b}}, \mathrm{p} 16^{\operatorname{lnk} 4 a}$, or $\mathrm{p} 19^{\text {Arf }}$ in the murine MSC model accelerates transformation. Using the 

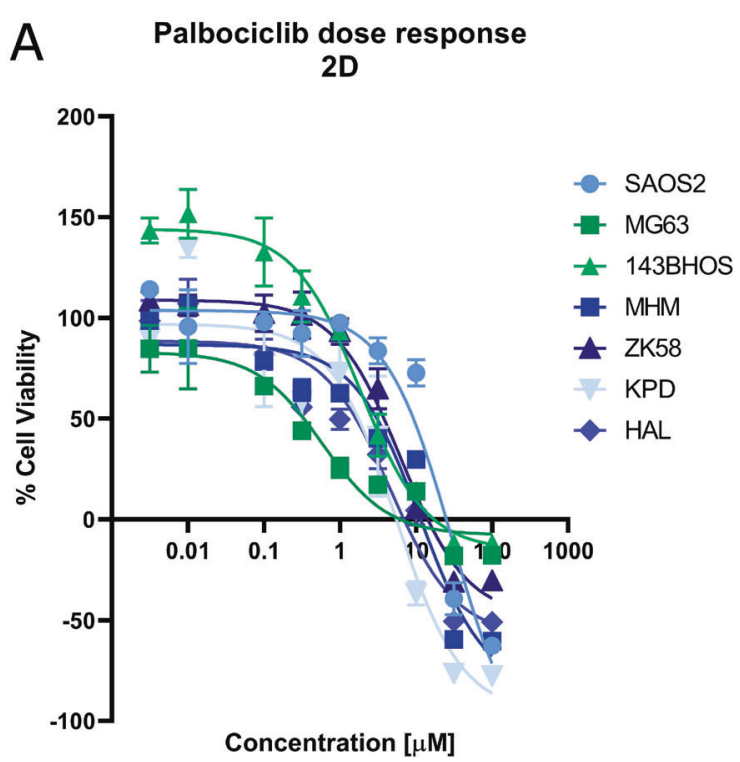

B

\begin{tabular}{|l|l|}
\hline Cell line & IC50 $(\boldsymbol{\mu M})$ \\
\hline SAOS2 & 10 \\
\hline MG63 & 0.32 \\
\hline 143BHOS & 2.51 \\
\hline MHM & 3.16 \\
\hline ZK58 & 3.98 \\
\hline KPD & 1.74 \\
\hline HAL & 1.58 \\
\hline
\end{tabular}
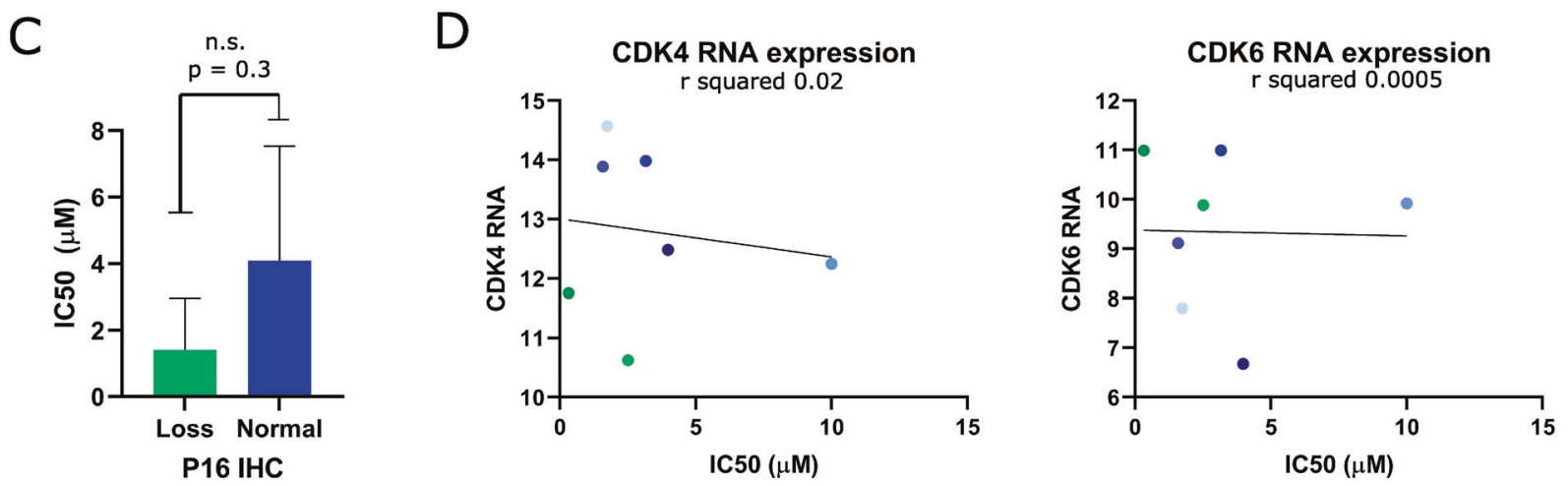

Fig. 4 2D cultures of human osteosarcoma cell lines are sensitive to CDK4/CDK6 inhibitor palbociclib. A Osteosarcoma cell lines were treated with palbociclib for $72 \mathrm{~h}$ after which relative cell viability and IC $\mathrm{C}_{50}$ values were determined. Cell lines MG63 and $143 \mathrm{BHOS}$ (green) have loss of p16, whereas other OS cell lines have intact p16 (blue). Data points represent the mean of three experiments performed \pm standard deviation. B Western blot showing expression levels of $\mathrm{Rb}$ in osteosarcoma cell lines. GAPDH was used as a loading control. C p16 protein expression status of each osteosarcoma cell line as published ${ }^{21}$ was correlated with $\mathrm{IC}_{50}$ values from the current study. n.s. not statistically significant. D CDK4 and CDK6 RNA expression levels as published elsewhere ${ }^{30}$ of each cell line did not correlate with $\mathrm{IC}_{50}$ values from the current study. Each dot represents one cell line.

same murine MSC model, we have previously published that these transformed murine MSCs, including those with loss of CDKN2A/ $C D K N 2 B$, show hallmarks of osteosarcoma with a highly complex genome and many copy number alterations ${ }^{19}$. Although chromothripsis could not be evaluated in the current study, not all human osteosarcomas show signs of chromothripsis either, since this only occurs in $\sim 30 \%$ of cases ${ }^{2}$. In another study, we have demonstrated that mice injected with transformed murine MSCs, all with loss of CDKN2A/CDKN2B, formed osteosarcoma, with evident osteoid formation by atypical tumour cells ${ }^{13}$. Thus, our results combined with previously published results, suggest that loss of CDKN2A/ $C D K N 2 B$ is an early driver event in osteosarcoma. Loss of genes in the Rb-p16 pathway is indeed considered as an early event in the transformation towards osteosarcoma ${ }^{7,36,37}$. The exact interplay with alterations in the p53 pathway is currently unknown, and since not all late passage murine MSCs with known loss of $p 16^{\text {Ink4a }}$ or p53 could form colonies in soft agar, it is not yet known which combination of genomic alterations are required for transformation. This would warrant further investigation.

Loss of p16 ${ }^{\text {INK4A }}$ protein expression as a result of homozygous loss of the CDKN2A genomic region has previously been shown to correlate with poor prognosis as well as a poor response to neoadjuvant chemotherapy in osteosarcoma patients ${ }^{13-18,25,38}$. Thus, studying the loss of p16 $6^{\mathrm{INK} 4 \mathrm{~A}}$ in osteosarcoma is clinically relevant and gives a rationale for exploring the Rb-p16 pathway as a novel therapeutic option. Cells with loss of p16 $16^{\text {INK4A }}$ are hypothesized to be more sensitive to CDK4/CDK6 inhibition. Therefore, we investigated the sensitivity to CDK4/CDK6 inhibitor palbociclib in osteosarcoma cells. We confirmed that both 2D and 3D cultures of osteosarcoma cells show a dose-dependent decrease in cell viability after palbociclib treatment. This is in line with other in vitro studies showing that pan-CDK or specific CDK4/ CDK6 inhibition in osteosarcoma resulted in growth inhibition of cells and increased senescence and/or apoptosis ${ }^{39,40}$.

In the current study, 2D cultures were more sensitive compared to $3 \mathrm{D}$ cultures. The difference in sensitivity is not surprising and could be explained by the formation of tight intercellular contacts within MCTS which may hamper drug penetration ${ }^{41}$. In general, the concentrations of palbociclib used in the current study, especially in 3D, are higher compared to concentrations used in the clinic for treatment of HER-2 negative breast cancer and in breast cancer cell lines in vitro ${ }^{42}$. However, we have treated the cells with a single dose, whereas in the clinic multiple doses are administered. Moreover, the $\mathrm{IC}_{50}$ values determined in the current study are in a comparable concentration 


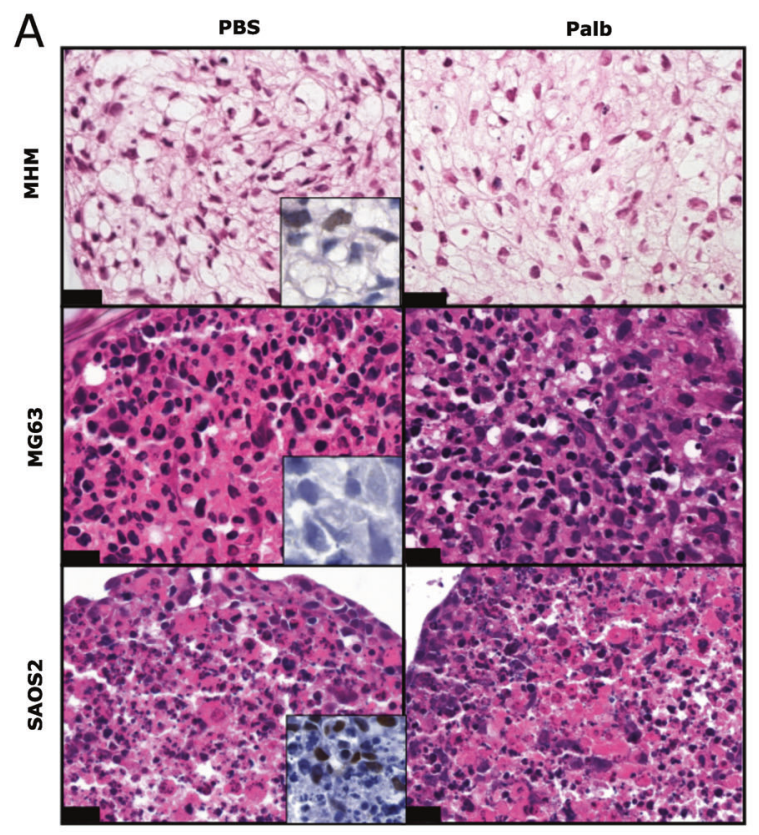

B

Palbociclib dose response

3D

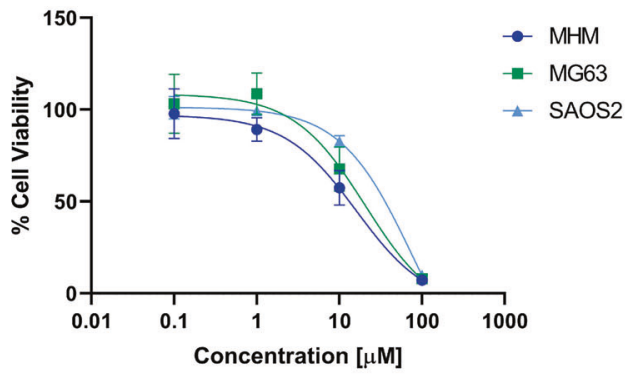

\begin{tabular}{|l|l|l|}
\hline Cell line & $\begin{array}{l}\text { IC50 3D } \\
(\boldsymbol{\mu M})\end{array}$ & $\begin{array}{l}\text { IC50 2D } \\
(\boldsymbol{\mu M})\end{array}$ \\
\hline SAOS2 & 34.1 & 10 \\
\hline MG63 & 17.7 & 0.32 \\
\hline MHM & 12.5 & 3.16 \\
\hline
\end{tabular}

C

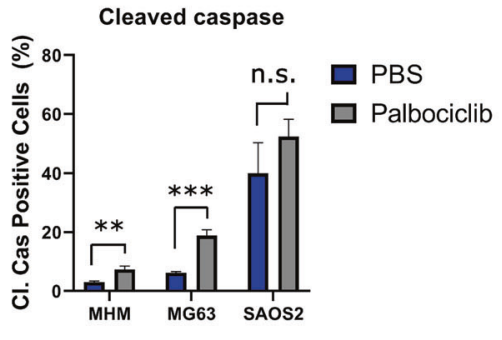

Cl. Cas 3
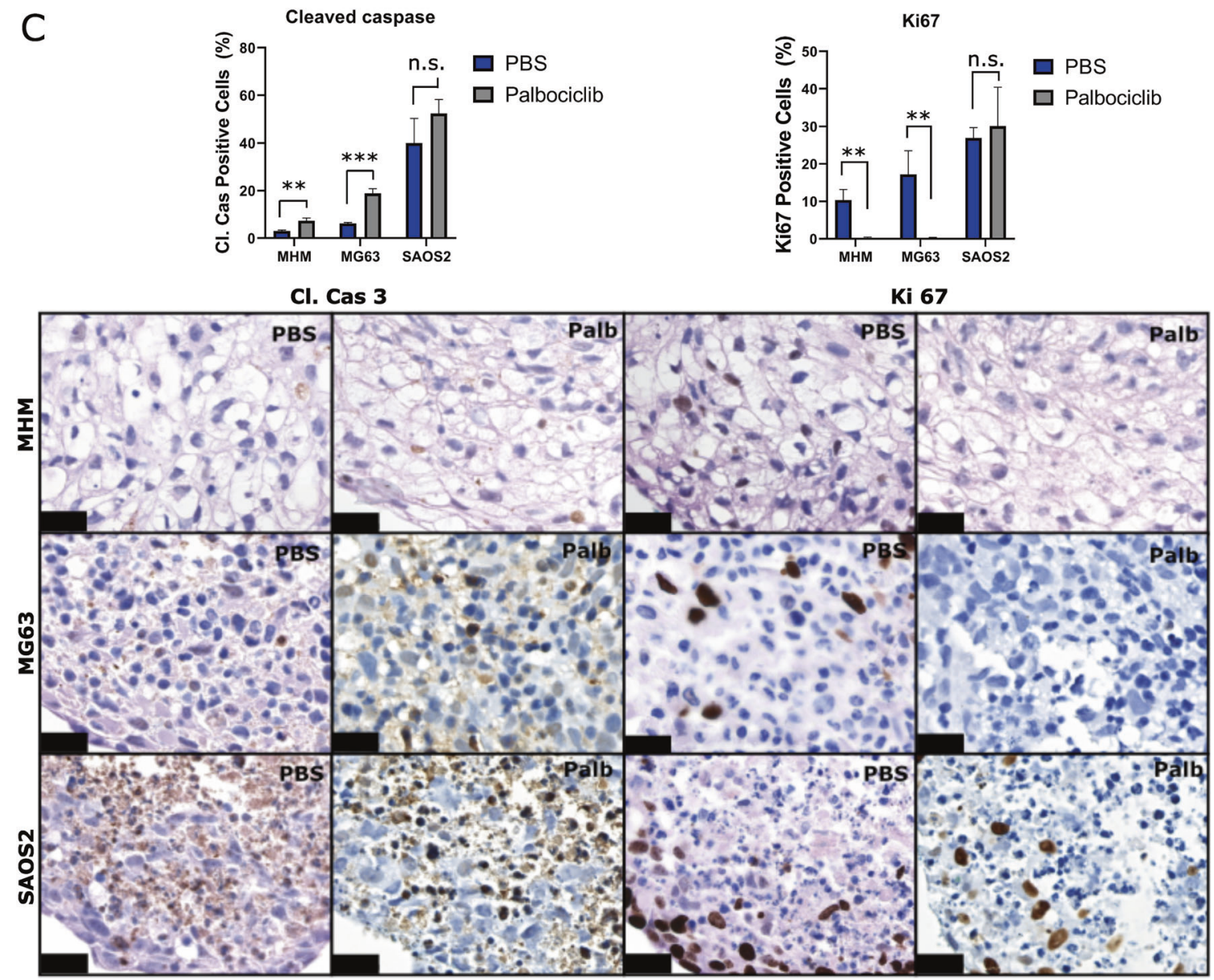

Fig. 5 3D cultured MCTS of osteosarcoma cell lines are also sensitive to palbociclib. A Hematoxylin and eosin staining of osteosarcoma MCTS treated with palbociclib for $72 \mathrm{~h}$. Scalebar represents $20 \mu \mathrm{m}$. Inset shows SATB2 staining. B Relative cell viability and IC 50 values were determined after treatment with palbociclib. C Cleaved caspase 3 and Ki67 staining and quantification of 3D cultured MCTS of OS cell lines treated with $10 \mu \mathrm{M}$ palbociclib (Palb) or PBS. Scale bar represents $20 \mu \mathrm{m}$. n.s. not statistically significant, ${ }^{* *} p \leq 0.01,{ }^{* * *} p \leq 0.001$. 
Table 1. Overview of immunohistochemical expression of Rb, CDK4 and CDK6, combined with previously published ${ }^{13}$ p16 protein expression results, in tissue micro-arrays of osteosarcoma.

\begin{tabular}{|c|c|c|c|c|}
\hline RB & $\begin{array}{l}\text { Primary tumour biopsy } \\
\text { Total }(n=66)\end{array}$ & $\begin{array}{l}\text { Primary tumour resection } \\
\text { Total }(n=68)\end{array}$ & $\begin{array}{l}\text { Local recurrence } \\
\text { Total }(n=9)\end{array}$ & $\begin{array}{l}\text { Metastasis } \\
\text { Total }(n=38)\end{array}$ \\
\hline positive & $42(63.6 \%)$ & $42(61.7 \%)$ & $6(66.7 \%)$ & $32(84.2 \%)$ \\
\hline negative & $24(36.4 \%)$ & $26(38.2 \%)$ & $3(33.3 \%)$ & $6(15.8 \%)$ \\
\hline CDK4 & Total $(n=76)$ & Total $(n=77)$ & Total $(n=9)$ & Total $(n=38)$ \\
\hline positive & $18(23.7 \%)$ & 15 (19.5\%) & $4(44.4 \%)$ & $7(18.4 \%)$ \\
\hline negative & $58(76.3 \%)$ & $62(80.5 \%)$ & $5(55.6 \%)$ & $31(81.6 \%)$ \\
\hline CDK6 & Total $(n=58)$ & Total $(n=56)$ & Total $(n=7)$ & Total $(n=26)$ \\
\hline high & $26(44.8 \%)$ & $32(57.1 \%)$ & $6(85.7 \%)$ & $12(46.2 \%)$ \\
\hline low & $32(56.2 \%)$ & $24(42.8 \%)$ & $1(14.3 \%)$ & $14(53.8 \%)$ \\
\hline \multicolumn{5}{|l|}{ Combination status } \\
\hline $\mathrm{RB}^{\text {positive }}$ and $\mathrm{CDK} 4^{\text {positive }}$ & $15 / 66(22.7 \%)$ & & & \\
\hline $\mathrm{RB}^{\text {positive }}$ and $\mathrm{CDK} 6^{\text {positive }}$ & $27 / 51(52.9 \%)$ & & & \\
\hline $\mathrm{RB}^{\text {positive }}$ and $\mathrm{CDK} 4^{\text {positive }}$ and $\mathrm{CDK} 6^{\text {positive }}$ & $6 / 51(11.8 \%)$ & & & \\
\hline $\mathrm{RB}^{\text {positive }}$ and $\mathrm{CDK} 4^{\text {positive }}$ or $\mathrm{CDK} 6^{\text {positive }}$ & $22 / 51(43.1 \%)$ & & & \\
\hline \multicolumn{5}{|l|}{ P16 (combination) status } \\
\hline $\mathrm{RB}^{\text {positive }}$ and $\mathrm{p} 16^{\text {negative }}$ & $4 / 30(13.3 \%)$ & & & \\
\hline $\mathrm{RB}^{\text {positive }} / \mathrm{p} 16^{\text {negative }}$ or $\mathrm{RB}^{\text {positive }} / \mathrm{CDK} 4^{\text {positive }}$ & $6 / 30(20.0 \%)$ & & & \\
\hline $\mathrm{RB}^{\text {positive }} / \mathrm{p} 16^{\text {negative }}$ or $\mathrm{RB}^{\text {positive }} / \mathrm{CDK}^{\text {positive }}$ & $7 / 30(23.3 \%)$ & & & \\
\hline
\end{tabular}

A

$\mathbf{R b}$

CDK4

CDK6

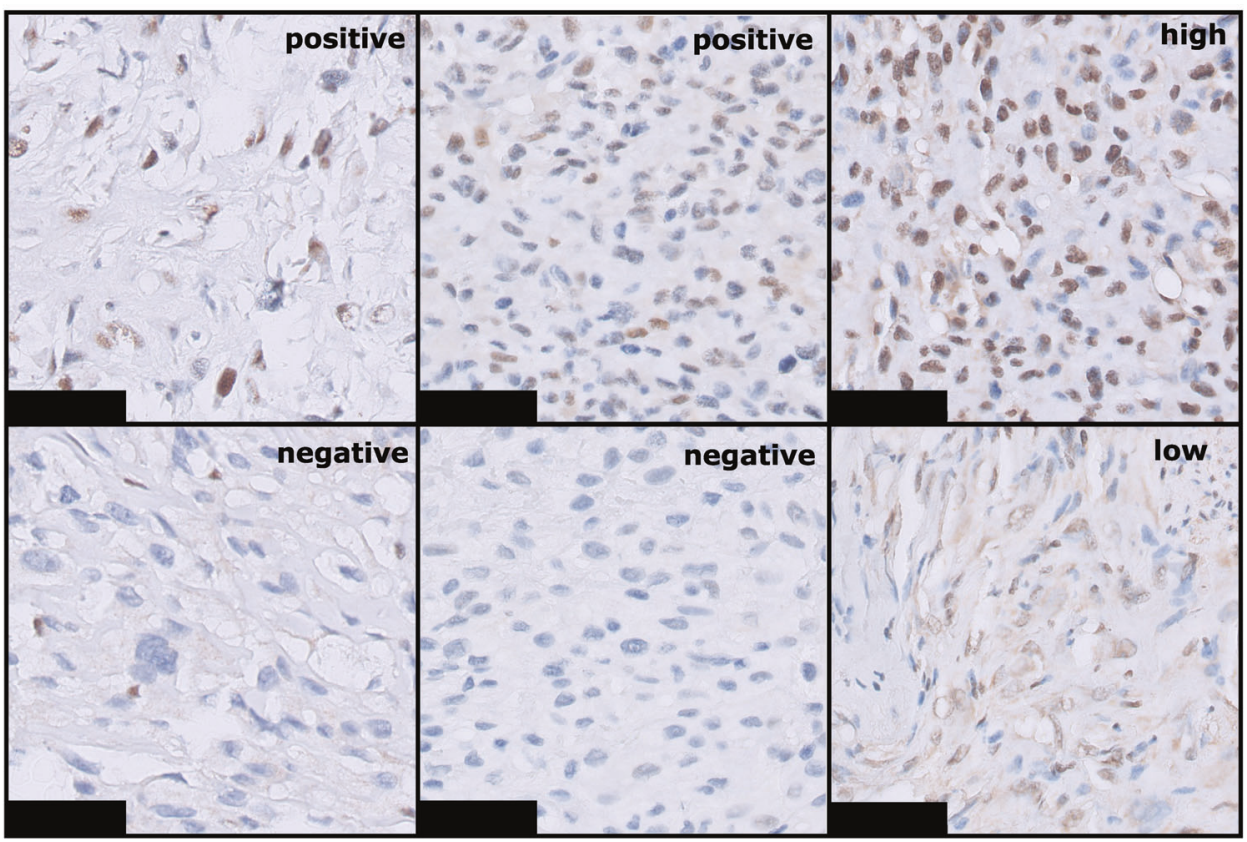

B

CDK6

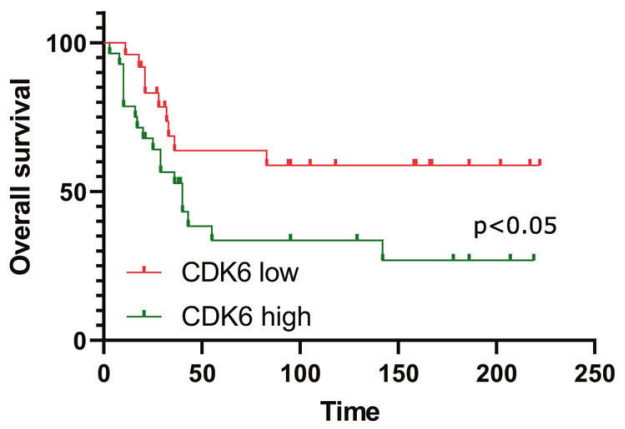

Fig. 6 Immunohistochemistry of osteosarcoma tissue micro array. A Example of immunohistochemical staining of Rb, CDK4, or CDK6, scored as positive or negative in tissue micro-arrays of osteosarcoma. Scale bar represents $50 \mu \mathrm{m}$. B Kaplan-Meier curves of overall survival in osteosarcoma patients, based on CDK6 scores. 
range when compared to other in vitro studies in osteosarcoma cells using palbociclib 39,40 . Thus, our data support previous findings that CDK4/CDK6 inhibition might be a new targeted treatment strategy for osteosarcoma patients ${ }^{40,43}$. However, more research is needed to investigate the efficacy of palbociclib for osteosarcoma patients, and whether there are any adverse effects. For the treatment of breast cancer, it was reported that the adverse effects of palbociclib include neutropenia, leukopenia or anaemia ${ }^{42,44}$.

Currently, two phase 2 clinical trials are ongoing which include advanced cases of sarcoma that overexpress CDK4, including osteosarcoma, for palbociclib treatment or similar CDK4/CDK6 inhibitors $^{45,46}$. One of these studies was also designed to test the utility of CDK4 expression in predicting tumour response to CDK inhibitors, but this study did not evaluate whether patients show loss of $\mathrm{p} 16^{\mathrm{INK} 4 \mathrm{~A}}$ or intact $\mathrm{Rb}$. In the current study sensitivity to palbociclib did not correlate with CDK4 expression in osteosarcoma cells.

Not only CDK4, but also CDK6 was evaluated as a prognostic and predictive biomarker in our study. Interestingly, about half of the osteosarcoma patients $(44.8 \%)$ showed overexpression of CDK6 which was associated with a worse overall survival. In this group of patients palbociclib could be beneficial to improve outcome. Palbociclib is most effective when $\mathrm{Rb}$ is intact, which was the case in approximately half $(52.9 \%)$ of the patients with CDK6 overexpression. The expression status of CDK4 and CDK6 is important to consider, since it was recently published that palbociclib selectively dissociates p21 from cyclin D1-CDK4-p21 complexes and not of cyclin D1-CDK6-p21 complexes, which could affect drug sensitivity and resistance ${ }^{47}$.

Another subgroup of osteosarcoma patients that might benefit from CDK4/CDK6 inhibition, include patients with intact $\mathrm{Rb}$, but loss of p16 expression. The in vitro study confirms that osteosarcoma cell lines with intact $\mathrm{Rb}$ and/or loss of $\mathrm{p} 16$ are more sensitive to palbociclib compared to osteosarcoma cell lines with loss of $\mathrm{Rb}$ and/or intact p16. Furthermore, osteosarcoma cell lines with loss of p16 staining by immunohistochemistry showed a trend towards higher sensitivity to palbociclib compared to cells without loss of p16. The immunohistochemical study on the tissue microarray indicates that $13.3 \%$ of the patients falls within this category of intact $\mathrm{Rb}$ and loss of p16 that may benefit from palbociclib treatment. Taken together, our results illustrate that there is a clear subset of osteosarcoma patients (20-23\%) for which CDK4/CDK6 inhibition might be promising and that loss of p16 protein expression or overexpression of CDK6, combined with intact $\mathrm{Rb}$, may serve as a biomarker to select eligible patients.

In conclusion, this study demonstrated that our model of transformed murine MSCs provide a valuable tool to identify targets for therapy and the identification of biomarkers for osteosarcoma patients. Our results illustrate that loss of CDKN2A and/or CDKN2B are early events in the development of osteosarcoma, and that these events can be targeted by CDK4/ CDK6 inhibition, which might be used as a novel therapeutic option in approximately $20-23 \%$ of the patients.

\section{DATA AVAILABILITY}

All data generated or analyzed during this study are included in this published article [and its supplementary information files].

\section{REFERENCES}

1. Behjati, S. et al. Recurrent mutation of IGF signalling genes and distinct patterns of genomic rearrangement in osteosarcoma. Nat. Commun. 8, 15936 (2017).

2. Stephens, P. J. et al. Massive genomic rearrangement acquired in a single catastrophic event during cancer development. Cell 144, 27-40 (2011).

3. Cortes-Ciriano, l. et al. Comprehensive analysis of chromothripsis in 2,658 human cancers using whole-genome sequencing. Nat. Genet. 52, 331-341 (2020).

4. Perry, J. A. et al. Complementary genomic approaches highlight the PI3K/mTOR pathway as a common vulnerability in osteosarcoma. Proc. Natl Acad. Sci. USA 111, E5564-E5573 (2014).
5. Kovac, M. et al. Exome sequencing of osteosarcoma reveals mutation signatures reminiscent of BRCA deficiency. Nat. Commun. 6, 8940 (2015).

6. Weinberg, R. The retinoblastoma protein and cell cycle control. Cell 81, 323-330 (1995).

7. Sayles, L. C. et al. Genome-informed targeted therapy for osteosarcoma. Cancer Discov. 9, 46-63 (2019).

8. Mejia-Guerrero, S., et al. Characterization of the 12q15MDM2and 12q1314CDK4amplicons and clinical correlations in osteosarcoma. Genes Chromosom. Cancer https://doi.org/10.1002/gcc.20761, NA-NA (2010).

9. Burkhart, D. L. \& Sage, J. Cellular mechanisms of tumour suppression by the retinoblastoma gene. Nat. Rev. Cancer 8, 671-682 (2008).

10. Sherr, C. J. \& Weber, J. D. The ARF/p53 pathway. Curr. Opin. Genet. Dev. 10, 94-99 (2000).

11. Miller, C. W. et al. Alterations of the p15, p16 and p18 Genes in Osteosarcoma. Cancer Genet. Cytogenet. 86, 136-142 (1996).

12. Tsuchiya, T. et al. Analysis of the p16INK4, p14ARF, p15, TP53, and MDM2 Genes and Their Prognostic Implications in Osteosarcoma and Ewing Sarcoma. Cancer Genet. Cytogenet. 120, 91-98 (2000).

13. Mohseny, A. B. et al. Osteosarcoma originates from mesenchymal stem cells in consequence of aneuploidization and genomic loss of Cdkn2. J. Pathol. 219, 294-305 (2009).

14. Righi, A. et al. p16 expression as a prognostic and predictive marker in high-grade localized osteosarcoma of the extremities: an analysis of 357 cases. Hum. Pathol. 58, 15-23 (2016).

15. Kosemehmetoglu, K., Ardic, F., Karslioglu, Y., Kandemir, O. \& Ozcan, A. p16 expression predicts neoadjuvant tumor necrosis in osteosarcomas: reappraisal with a larger series using whole sections. Hum. Pathol. 50, 170-175 (2016).

16. $\mathrm{Bu}, \mathrm{J}$., et al. P16Ink4a overexpression and survival in osteosarcoma patients: a meta analysis. Int. J. Clin. Exp. Pathol. 7, 6091-6096 (2014).

17. Borys, D. et al. P16 expression predicts necrotic response among patients with osteosarcoma receiving neoadjuvant chemotherapy. Hum. Pathol. 43, 1948-1954 (2012).

18. Maitra, A., Roberts, H., Weinberg, A. \& Geradts, J. Loss of p16ink4a expression correlates with decreased survival in pediatric osteosarcomas. Int. J. Cancer 95, 34-8 (2001).

19. Franceschini, N., et al. Transformed murine and canine mesenchymal stem cells as a model for sarcoma with complex genomics. Cancers 13, 1126 (2021).

20. Krimpenfort, P. et al. p15Ink4b is a critical tumour suppressor in the absence of p16Ink4a. Nature 448, 943-946 (2007).

21. Ottaviano, L. et al. Molecular characterization of commonly used cell lines for bone tumor research: a trans-European EuroBoNet effort. Genes Chromosom. Cancer 49, 40-51 (2010).

22. Zhang, W. et al. Optimization of the formation of embedded multicellular spheroids of MCF-7 cells: how to reliably produce a biomimetic 3D model. Anal. Biochem. 515, 47-54 (2016).

23. Hafner, M., Niepel, M., Chung, M. \& Sorger, P. K. Growth rate inhibition metrics correct for confounders in measuring sensitivity to cancer drugs. Nat. Methods 13, 521-527 (2016).

24. WHO Classification of Tumours of Soft Tissue and Bone 5th edn, Vol. 3 (WHO Classification of Tumours Editorial Board, 2020).

25. Mohseny, A. B. et al. Small deletions but not methylation underlie CDKN2A/p16 loss of expression in conventional osteosarcoma. Genes Chromosom. Cancer 49, 1095-1103 (2010).

26. Buddingh, E. P. et al. Tumor-infiltrating macrophages are associated with metastasis suppression in high-grade osteosarcoma: a rationale for treatment with macrophage activating agents. Clin. Cancer Res. 17, 2110-2119 (2011).

27. Schrage, Y. M. et al. Central chondrosarcoma progression is associated with $\mathrm{pRb}$ pathway alterations: CDK4 down-regulation and p16 overexpression inhibit cell growth in vitro. J. Cell Mol. Med. 13, 2843-2852 (2009).

28. Gong, W. et al. Cyclin-dependent kinase 6 (CDK6) is a candidate diagnostic biomarker for early non-small cell lung cancer. Transl. Cancer Res. 9, 95-103 (2020).

29. Bankhead, P. et al. QuPath: open source software for digital pathology image analysis. Sci. Rep. 7, 16878 (2017).

30. Kresse, S. H. et al. Integrative analysis reveals relationships of genetic and epigenetic alterations in osteosarcoma. PLOS ONE 7, e48262 (2012).

31. Chow, T., et al. Creating in vitro three-dimensional tumor models: a guide for the biofabrication of a primary osteosarcoma model. Tissue Eng. Part B https://doi. org/10.1089/ten.teb.2020.0254 (2020).

32. De Luca, A. et al. Relevance of $3 d$ culture systems to study osteosarcoma environment. J. Exp. Clin. Cancer Res. 37, 2 (2018).

33. Gao, S., Shen, J., Hornicek, F. \& Duan, Z. Three-dimensional (3D) culture in sarcoma research and the clinical significance. Biofabrication 9, 032003 (2017).

34. Sherr, C. J., Beach, D. \& Shapiro, G. I. Targeting CDK4 and CDK6: from discovery to therapy. Cancer Discov. 6, 353-367 (2016). 
35. Guha, M. Cyclin-dependent kinase inhibitors move into Phase III. Nat. Rev. Drug Discov. 11, 892-894 (2012).

36. Kovac, M., et al. The early evolutionary landscape of osteosarcoma provides clues for targeted treatment strategies. J. Pathol. https://doi.org/10.1002/path.5699 (2021).

37. Mohseny, A. B., Hogendoorn, P. C. \& Cleton-Jansen, A. M. Osteosarcoma models: from cell lines to zebrafish. Sarcoma 2012, 417271 (2012).

38. Tang, Y., et al. P16 protein expression as a useful predictive biomarker for neoadjuvant chemotherapy response in patients with high-grade osteosarcoma. Medicine 96, e6714 (2017).

39. Zhou, Y. et al. Expression and therapeutic implications of cyclin-dependent kinase 4 (CDK4) in osteosarcoma. Biochim. Biophys. Acta Mol. Basis Dis. 1864, 1573-1582 (2018).

40. Perez, M., Galván, S. M., García, M. P., Marín, J. J. \& Carnero, A. Efficacy of CDK4 inhibition against sarcomas depends on their levels of CDK4 and p16ink4 mRNA. Oncotarget 6, 40557-74 (2015).

41. Gong, X. et al. Generation of multicellular tumor spheroids with microwell-based agarose scaffolds for drug testing. PLOS ONE 10, e0130348 (2015).

42. Cristofanilli, M. et al. Fulvestrant plus palbociclib versus fulvestrant plus placebo for treatment of hormone-receptor-positive, HER2-negative metastatic breast cancer that progressed on previous endocrine therapy (PALOMA-3): final analysis of the multicentre, double-blind, phase 3 randomised controlled trial. Lancet Oncol. 17, 425-439 (2016).

43. Delmore, J. E. et al. BET bromodomain inhibition as a therapeutic strategy to target c-Myc. Cell 146, 904-917 (2011).

44. Finn, R. S. et al. Palbociclib and letrozole in advanced breast cancer. N. Engl. J. Med. 375, 1925-1936 (2016).

45. Trial of Palbociclib in Second Line of Advanced Sarcomas With CDK4 Overexpression, https://clinicaltrials.gov/ct2/show/study/NCT03242382 Accessed 18-01-2021.

46. Abemaciclib for Bone and Soft Tissue Sarcoma With Cyclin-Dependent Kinase (CDK) Pathway Alteration, https://clinicaltrials.gov/ct2/show/NCT04040205 Accessed 1801-2021.

47. Pack, L. R., Daigh, L. H., Chung, M. \& Meyer, T. Clinical CDK4/6 inhibitors induce selective and immediate dissociation of p21 from cyclin D-CDK4 to inhibit CDK2. Nat. Commun. 12, 3356 (2021)

\section{ACKNOWLEDGEMENTS}

The authors would like to thank Melissa van Pel for providing murine MSCs; Pauline Wijers-Koster and Brendy van den Akker for technical assistance; Marieke Kuijjer and René Zwartbol for the generation of the TMAs; Michiel van de Sande for the clinical data used in the tissue micro arrays; Dirk-Jan Moes for discussions about the physiological concentration range of palbociclib.

\section{AUTHOR CONTRIBUTIONS}

N.F., J.V.M.G.B. and A.M.C.J. designed the study. N.F. performed all MSC culture experiments. R.G. and N.F. scored all tissue micro-arrays, with J.V.M.G.B. scoring any discrepancies. A.K. and I.B. performed Western blotting and immunohistochemistry experiments. P.K. provided all FVB mice for this study. N.F., J.V.M.G.B. and A.M.C.J. analyzed the data. All authors contributed to and approved the final version of the manuscript.

\section{FUNDING}

This work was financially supported by the Netherlands Organization for Scientific Research (ZON-MW VICI 170.055 to J.V.M.G.B.).

\section{COMPETING INTERESTS}

The authors declare no competing interests.

\section{ETHICS APPROVAL AND CONSENT TO PARTICIPATE}

All samples were handled according to the ethical guidelines described in "Code for Proper Secondary Use of Human Tissue in the Netherlands" in a coded (pseudonymized) manner, as approved by the Leiden University Medical Center ethical board (B17.036).

\section{ADDITIONAL INFORMATION}

Supplementary information The online version contains supplementary material available at https://doi.org/10.1038/s41374-021-00709-z.

Correspondence and requests for materials should be addressed to Judith V. M. G. Bovée.

Reprints and permission information is available at http://www.nature.com/ reprints

Publisher's note Springer Nature remains neutral with regard to jurisdictional claims in published maps and institutional affiliations. (c) (i)

Open Access This article is licensed under a Creative Commons Attribution 4.0 International License, which permits use, sharing, adaptation, distribution and reproduction in any medium or format, as long as you give appropriate credit to the original author(s) and the source, provide a link to the Creative Commons license, and indicate if changes were made. The images or other third party material in this article are included in the article's Creative Commons license, unless indicated otherwise in a credit line to the material. If material is not included in the article's Creative Commons license and your intended use is not permitted by statutory regulation or exceeds the permitted use, you will need to obtain permission directly from the copyright holder. To view a copy of this license, visit http://creativecommons. org/licenses/by/4.0/.

(c) The Author(s) 2021 